DRUG DISCOVERY AND RESISTANCE

\title{
Antimycobacterial activity of pyrazinoate prodrugs in replicating and non-replicating Mycobacterium tuberculosis
}

\author{
Natanael Dante Segretti ${ }^{a}$, Cristina Kortstee Simões ${ }^{b}$, Michelle Fidelis Corrêa ${ }^{b}$, \\ Veni Maria Andres Felli ${ }^{a}$, Marcelo Miyata ${ }^{\mathrm{c}}$, Sang Hyun Cho ${ }^{\mathrm{d}}$, Scott Gary Franzblau ${ }^{\mathrm{d}}$, \\ João Paulo dos Santos Fernandes b, * \\ a Departamento de Farmácia, Faculdade de Ciências Farmacêuticas, Universidade de São Paulo, Av. Prof. Lineu Prestes 580, 05508-000 Butantã, São Paulo, \\ SP, Brazil \\ ${ }^{\mathrm{b}}$ Departamento de Ciências Exatas e da Terra, Instituto de Ciências Ambientais, Químicas e Farmacêuticas, Universidade Federal de São Paulo, Rua São \\ Nicolau 210, 09913-030 Centro, Diadema, SP, Brazil \\ c Departamento de Ciências Biológicas, Faculdade de Ciências Farmacêuticas, Universidade Estadual Paulista "Júlio de Mesquita Filho", Rodovia Araraquara- \\ Jaú km 1, 14801-902, Araraquara, SP, Brazil \\ ${ }^{\mathrm{d}}$ Institute for Tuberculosis Research, College of Pharmacy, University of Illinois at Chicago, 833 S. Wood St., 60612-7231 Chicago, IL, USA
}

\section{A R T I C L E I N F O}

\section{Article history:}

Received 16 June 2015

Received in revised form

31 March 2016

Accepted 5 April 2016

\section{Keywords:}

Antimycobacterial prodrug

Duplicated prodrug

LORA assay

Pyrazinoate ester

\begin{abstract}
S U M M A R Y
Tuberculosis (TB) is an important infectious disease caused by Mycobacterium tuberculosis (Mtb) and responsible for thousands of deaths every year. Although there are antimycobacterial drugs available in therapeutics, just few new chemical entities have reached clinical trials, and in fact, since introduction of rifampin only two important drugs had reached the market. Pyrazinoic acid (POA), the active agent of pyrazinamide, has been explored through prodrug approach to achieve novel molecules with anti-Mtb activity, however, there is no activity evaluation of these molecules against non-replicating Mtb until the present. Additionally, pharmacokinetic must be preliminary evaluated to avoid future problems during clinical trials. In this paper, we have presented six POA esters as prodrugs in order to evaluate their anti-Mtb activity in replicating and non-replicating Mtb, and these showed activity highly influenced by medium composition (especially by albumin). Lipophilicity seems to play the main role in the activity, possibly due to controlling membrane passage. Novel duplicated prodrugs of POA were also described, presenting interesting activity. Cytotoxicity of these prodrugs set was also evaluated, and these showed no important cytotoxic profile.
\end{abstract}

(C) 2016 Elsevier Ltd. All rights reserved.

\section{Introduction}

Tuberculosis (TB) is an infectious disease caused by members of the Mycobacterium tuberculosis (Mtb) complex and comprising one of the most important infectious diseases. Although the antimycobacterial drugs available until present led to controlled TB prevalence rates by several decades, the appearance of resistant cases brought TB to a worrying status [1,2]. Moreover, the incidence of TB has risen in the last years. In particular, the incidence of multidrug-resistant TB (MDR-TB) and extensively drug-resistant TB (XDR-TB) is also increasing, and become the major health concern

\footnotetext{
* Corresponding author. Tel.: +55 1133193578 .

E-mail address: joao.fernandes@unifesp.br (J.P.S. Fernandes).
}

worldwide [1]. This scenario highlights the importance of design and development of new anti-TB drugs to handle future TB cases.

Nowadays, the treatment of TB is mainly performed in a 6month regimen. It is widely accepted at present that the physiological state of non-replicating persistence (NRP) subpopulation of mycobacteria is responsible for the antimycobacterial tolerance, as well as the key to shortening the long treatment regimen. It is highly appreciated that new anti-TB agents to be effective against this subpopulation to achieve this goal [3]. The low-oxygenrecovery assay (LORA) [3] is a method considered adequate to identify hits and lead compounds active in this subpopulation. Several examples of bioactive compounds were identified using this approach, such as quinolines [4], quinoxalines [5], arylbenzylpurines, aza- and deaza-purines [6] and aminothiazoles [7].

PZA (Figure 1) is a first-line agent to TB control in several countries (including Brazil). PZA is one of the most efficient agents 
<smiles>NC(=O)c1cnccn1</smiles>

PZA

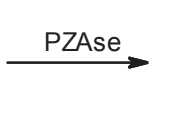

Figure 1. PZA and POA esters activation pathways.

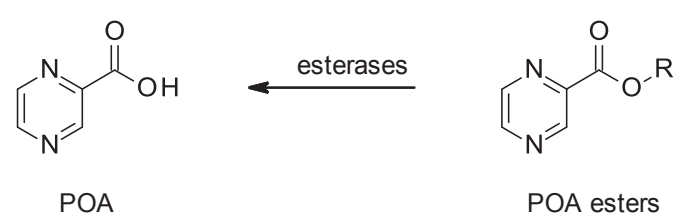

POA esters in killing Mtb inside the granuloma, where slow-growing bacilli are found. PZA interferes with the membrane energy metabolism and function [8] possibly through competitive inhibition of NADPH binding in Mtb fatty acid synthase-I (FAS-I) [9]. Additionally, PZA is more active in acidic conditions [8]. However, its exact mechanism of action remains unknown. The Zhang's hypothesis [8] establishes that PZA actions could be, at least partially, dependent of its conversion to the active acid metabolite, pyrazinoic acid (POA), since some PZA-resistant strains do not express the enzyme responsible for the conversion of PZA into POA (named as nicotinamidase/ pyrazinamidase, PZAse). It was verified that the PZA conversion to POA (Figure 1) could play the main role in PZA resistance [10-12]. Given the characteristics of POA, prodrug approach is a feasible method to transport POA inside Mtb, allowing it to exert its antimycobacterial activity. Several POA esters (Figure 1) were already synthesized and evaluated as prodrugs of POA, which must be activated by mycobacterial esterases. After hydrolysis, these esters (Figure 1) have shown activity even in strains that do not express PZAse, corroborating to Zhang's hypothesis [8].

Although POA esters are important alternatives to be considered in resistant TB strains, they did not achieve the therapeutics yet. Among the problems encountered during their development, poor stability in horse plasma was verified due to rapid hydrolysis by plasmatic esterases [2,12]. Important pharmacokinetic parameters, as protein binding, were also not evaluated for these molecules, and it is widely known the role of pharmacokinetic to the success of a drug candidate. Moreover, the activity of POA esters in NRP Mtb were not been studied yet. Herein, we report the activity of POA esters in replicating and non-replicating Mtb, the influence of albumin on its activity, and considering POA as the active agent after hydrolysis, two novel duplicate prodrugs of POA were designed and evaluated.

\section{Materials and methods}

\subsection{Chemistry}

Chemicals were purchased in adequate purity from commercial sources. Six POA prodrugs were synthesized following two methods ( $A$ and $B$ ). Method A was used to prepare compounds 1-3 and method $B$ to prepare compound 4 . The remaining molecules (5-6) were prepared using method C. Some of these methods were already published previously by our group $[2,13]$. The final tested compounds (1-6, Figure 2 ) are presented in Tables $1-3$.

\subsubsection{Method $A$}

$5 \mathrm{mmol}$ of POA $(0.620 \mathrm{~g})$ were dissolved in $10 \mathrm{~mL}$ of appropriate alcohol (methanol or ethanol), and $7 \mathrm{mmol}$ of thionyl chloride $(0.5 \mathrm{~mL})$ were added. The mixture was then heated to $60{ }^{\circ} \mathrm{C}$ and stirred for $3 \mathrm{~h}$. The solvent was evaporated, and the oily residue was taken up in $10 \mathrm{~mL}$ of ethyl acetate, and washed twice with $10 \mathrm{~mL}$ of saturated aqueous $\mathrm{NaHCO}_{3}$, and $10 \mathrm{~mL}$ of distilled water. The organic phase was dried using anhydrous $\mathrm{Na}_{2} \mathrm{SO}_{4}$, and the solvent evaporated. Methyl pyrazinoate (1), 83\% yield. 4.07 (s, 3H, $\left.\mathrm{CH}_{3}\right)$, $8.75(\mathrm{dd}, J=2.4,1.4 \mathrm{~Hz}, 1 \mathrm{H}, \mathrm{CHC} \underline{H N C H}), 8.80$ (d, $J=2.4 \mathrm{~Hz}, 1 \mathrm{H}$,
CHCHNCH), 9.35 (d, $J=1.4 \mathrm{~Hz}, 1 \mathrm{H}, \mathrm{CHCHNCH}) .{ }^{13} \mathrm{C} \mathrm{NMR}\left(\mathrm{CDCl}_{3}\right.$, $7 \overline{5} \mathrm{MHz}, \delta=\mathrm{ppm}) 53.2\left(\mathrm{CH}_{3}\right), 143.4(\mathrm{NCC}=\mathrm{O}), 144.4(\mathrm{CHNC}), 146.3$ (NCHC), 147.8 ( $\underline{\mathrm{CHNCHC}}), 164.4(\mathrm{C}=\mathrm{O})$. Ethyl pyrazinoate $(\mathbf{2}), 80 \%$ yield. ${ }^{1} \mathrm{H}$ NMR $\left(\mathrm{CDCl}_{3}, 300 \mathrm{MHz}, \delta=\mathrm{ppm}\right) 1.47(\mathrm{t}, J=7.1 \mathrm{~Hz}, 3 \mathrm{H}$, $\left.\mathrm{CH}_{3}\right), 4.53\left(\mathrm{q}, J=7.1 \mathrm{~Hz}, 2 \mathrm{H}, \mathrm{CH}_{2}\right), 8.74(\mathrm{dd}, J=2.4,1.4 \mathrm{~Hz}, 1 \mathrm{H}$, CHCHNCH), $8.78(\mathrm{~d}, J=2.4 \mathrm{~Hz}, 1 \mathrm{H}, \mathrm{CHCHNCH}), 9.33(\mathrm{~d}, J=1.4 \mathrm{~Hz}$, $1 \mathrm{H}, \overline{\mathrm{CHCHNCH}}) .{ }^{13} \mathrm{C} \mathrm{NMR}\left(\mathrm{CDCl}_{3}, 75 \mathrm{MHz}, \delta=\mathrm{ppm}\right) 14.3\left(\mathrm{CH}_{3}\right), 62.5$ $\left(\mathrm{CH}_{2}\right), 143.7$ (NCC $\left.=\mathrm{O}\right), 144.5$ ( $\left.\underline{\mathrm{CHNC}}\right), 146.4$ (NCHC), 147.7 (CHNCHC), $164.0 \overline{(\mathrm{C}=0)}$. 2-Chloroethyl pyrazinoate $(\mathbf{3}), 85 \%$ yield. ${ }^{1} \mathrm{H}$ NMR $\left(\mathrm{CDCl}_{3}, 300 \mathrm{MHz}, \delta=\mathrm{ppm}\right) 3.95\left(\mathrm{t}, J=5.6 \mathrm{~Hz}, 2 \mathrm{H}, \mathrm{CH}_{2} \mathrm{Cl}\right)$, $4.75\left(\mathrm{t}, J=5.6 \mathrm{~Hz}, 2 \mathrm{H}, \mathrm{CH}_{2} \mathrm{O}\right), 8.82(\mathrm{dd}, J=2.4,1.4 \mathrm{~Hz}, 1 \mathrm{H}$, $\mathrm{CHCHNCH}), 8.87$ (d, $J=2.4 \mathrm{~Hz}, 1 \mathrm{H}, \mathrm{CHCHNCH}), 9.34$ (d, $J=1.4 \mathrm{~Hz}$, $1 \mathrm{H}, \overline{\mathrm{C}} \mathrm{HCHNCH}) .{ }^{13} \mathrm{C}$ NMR $\left(\mathrm{CDCl}_{3}, 75 \overline{\mathrm{MHz}}, \delta=\mathrm{ppm}\right) 41.2\left(\mathrm{CH}_{2} \mathrm{Cl}\right)$, $65.5\left(\mathrm{CH}_{2} \mathrm{O}\right), 143.1$ ( $\left.\underline{\mathrm{CC}}=\mathrm{O}\right), 144.6$ ( $\left.\underline{\mathrm{CHNC}}\right), 146.4$ (NCHC), 148.0 ( $\underline{\mathrm{CHNCHC}}), 163.5(\mathrm{C}=\overline{\mathrm{O}})$.

\subsubsection{Method $B$}

$5 \mathrm{mmol}$ of POA $(0.620 \mathrm{~g}), 5 \mathrm{mmol}$ of triethylamine $(0.505 \mathrm{~g})$ and $6 \mathrm{mmol}$ of 1 -bromohexane $(0.990 \mathrm{~g})$ were dissolved in $10 \mathrm{~mL}$ of acetone. The reaction mixture was stirred under reflux for $12 \mathrm{~h}$, and the solvent was then evaporated. The residue was taken up in $10 \mathrm{~mL}$ of ethyl acetate, and washed twice with $10 \mathrm{~mL}$ of distilled water. The organic phase was dried using anhydrous $\mathrm{Na}_{2} \mathrm{SO}_{4}$, and the solvent evaporated. The crude product was purified using flash column chromatography, using hexane:ethyl acetate $(2: 1)$ as eluent. Hexyl pyrazinoate (4), 76\% yield. ${ }^{1} \mathrm{H} \mathrm{NMR}\left(\mathrm{CDCl}_{3}, 300 \mathrm{MHz}\right.$, $\delta=\mathrm{ppm}) 0.90\left(\mathrm{t}, J=7.0 \mathrm{~Hz}, 3 \mathrm{H}, \mathrm{CH}_{3}\right), 1.28-1.51(\mathrm{~m}, 6 \mathrm{H}$, $\mathrm{CH}_{2} \mathrm{CH}_{2} \mathrm{CH}_{2} \mathrm{CH}_{3}$ ), 1.84 (quint, $J=6.8 \mathrm{~Hz}, 2 \mathrm{H}, \mathrm{CH}_{2} \mathrm{CH}_{2} \mathrm{O}$ ), 4.45 (t, $\left.J=6 . \overline{8} \mathrm{~Hz}, 2 \mathrm{H}, \mathrm{CH}_{2} \mathrm{O}\right), 8.74(\mathrm{dd}, J=2.4,1.4 \mathrm{~Hz}, 1 \mathrm{H}, \mathrm{CHCHNCH}), 8.77$ $(\mathrm{d}, J=2.4 \mathrm{~Hz}, 1 \mathrm{H}, \mathrm{C} H \mathrm{CHNCH}), 9.31(\mathrm{~d}, J=1.4 \mathrm{~Hz}, 1 \mathrm{H}, \mathrm{CHC} \mathrm{HNCH}) .{ }^{13} \mathrm{C}$ NMR $\left(\mathrm{CDCl}_{3}, 75 \mathrm{MHz}, \delta=\mathrm{ppm}\right) 14.0\left(\mathrm{CH}_{3}\right), 22.5\left(\mathrm{CH}_{3} \underline{C H}_{2}\right), 25.6$ $\left(\mathrm{CH}_{2} \mathrm{CH}_{2} \mathrm{CH}_{2} \mathrm{O}\right), 28.6\left(\mathrm{CH}_{2} \mathrm{CH}_{2} \mathrm{O}\right), 31.4\left(\mathrm{CH}_{3} \mathrm{CH}_{2} \mathrm{CH}_{2}\right), 66.5\left(\mathrm{CH}_{2} \mathrm{O}\right)$, $143.7(\mathrm{NCC}=0), 144.5$ ( $\underline{C} \mathrm{HNC}), 146.3$ (NCHC), 147.6 ( $\underline{\mathrm{CHNCHC}}), 164.0$ $(\mathrm{C}=\mathrm{O})$.

\subsubsection{Method C}

$12 \mathrm{mmol}$ of POA (1.488 g) were dissolved in $10 \mathrm{~mL}$ of acetone, and $5 \mathrm{mmol}$ of adequate dialkylating agent (1,2-dibromoethane, $0.940 \mathrm{~g}$, or 1,3-dibromopropane, $1.010 \mathrm{~g}$ ) and $10 \mathrm{mmol}$ of triethylamine $(1.100 \mathrm{~g})$ were added. The reaction mixture was stirred under reflux for $12 \mathrm{~h}$, and the solvent was then evaporated. The residue was taken up in $10 \mathrm{~mL}$ of ethyl acetate, and washed twice with $10 \mathrm{~mL}$ of aqueous $\mathrm{NaHCO}_{3}$, and $10 \mathrm{~mL}$ of distilled water. The organic phase was dried using anhydrous $\mathrm{Na}_{2} \mathrm{SO}_{4}$, and the solvent evaporated. The crude product was purified using flash column chromatography, using hexane:ethyl acetate $(2: 1)$ as eluent. 2(Pyrazinoyloxy)ethyl pyrazinoate (5), 60\% yield. ${ }^{1} \mathrm{H}$ NMR $\left(\mathrm{CDCl}_{3}\right.$, $300 \mathrm{MHz}, \delta=\mathrm{ppm}) 4.85\left(\mathrm{~s}, 4 \mathrm{H}, 2 \mathrm{x} \mathrm{CH}_{2}\right), 8.74(\mathrm{dd}, J=2.4,1.5 \mathrm{~Hz}, 2 \mathrm{H}$, 2x CHCHNCH), 8.78 (d, $J=2.4 \mathrm{~Hz}, 2 \mathrm{H}, 2 \mathrm{x} \mathrm{CHCHNCH}$ ), 9.32 (d, $J=1.5 \mathrm{~Hz}, 2 \mathrm{H}, 2 \mathrm{x} \mathrm{CHCHNCH}) .{ }^{13} \mathrm{C} \mathrm{NMR}\left(\mathrm{CDCl}_{3}, 75 \mathrm{MHz}, \delta=\mathrm{ppm}\right)$ $63.6\left(\mathrm{CH}_{2}\right), 143.0(\mathrm{NCC}=\overline{0}), 144.5(\underline{\mathrm{CHNC}}), 146.5(\mathrm{~N} \underline{\mathrm{CHC}}), 148.0$ (CHNCHC), $163.8(\mathrm{C}=\overline{\mathrm{O}})$. 3-(Pyrazinoyloxy)propyl pyrazinoate $(\mathbf{6})$, $63 \%$ yield. ${ }^{1} \mathrm{H} \mathrm{NMR}\left(\mathrm{CDCl}_{3}, 300 \mathrm{MHz}, \delta=\mathrm{ppm}\right) 2.40$ (quint, $\left.J=6.2 \mathrm{~Hz}, 2 \mathrm{H}, \mathrm{CH}_{2} \mathrm{CH}_{2} \mathrm{CH}_{2}\right), 4.65\left(\mathrm{t}, J=6.2 \mathrm{~Hz}, 4 \mathrm{H}, 2 \mathrm{x} \mathrm{CH} \mathrm{CH}_{2} \mathrm{O}\right), 8.71$ (dd, $J=2.4,1.5 \mathrm{~Hz}, \overline{2} \mathrm{H}, 2 \mathrm{x} \mathrm{CHCHNCH}), 8.77$ (d, $J=2.4 \mathrm{~Hz}, 2 \mathrm{H}, 2 \mathrm{x}$ 


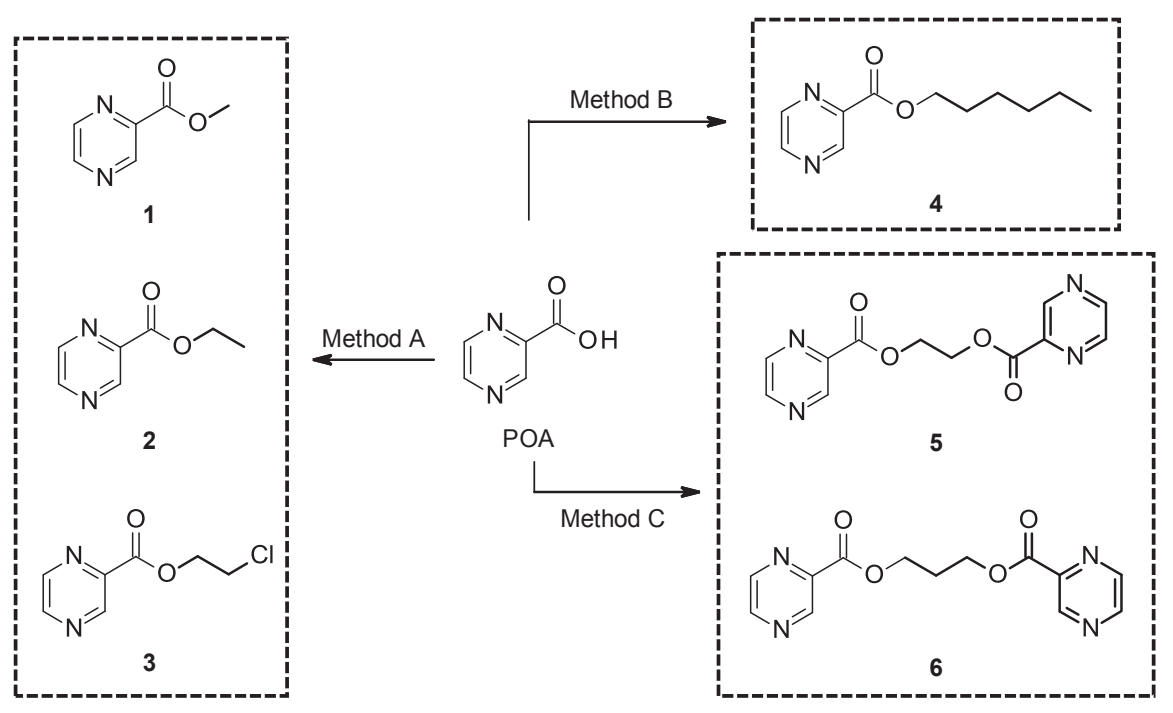

Figure 2. POA esters.

$\mathrm{CHCHNCH}), 9.32(\mathrm{~d}, \mathrm{~J}=1.5 \mathrm{~Hz}, 2 \mathrm{H}, 2 \mathrm{x} \mathrm{CHCHNCH}) .{ }^{13} \mathrm{C} \mathrm{NMR}\left(\mathrm{CDCl}_{3}\right.$, $7 \overline{5} \mathrm{MHz}, \delta=\mathrm{ppm}) 28.0\left(\mathrm{CH}_{2}\right) 62.9\left(\mathrm{CH}_{2} \mathrm{O}\right), 14 \overline{3.3}(\mathrm{NCC}=\mathrm{O}), 144.4$

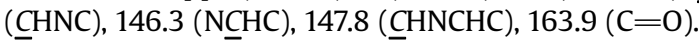

\subsection{Anti-Mtb assays}

Samples (synthetic products and standards) stock solutions were prepared in DMSO with adequate starting concentrations. The minimum inhibitory concentrations (MICs) against replicating M. tuberculosis $\mathrm{H}_{37} \mathrm{Rv}$ (ATCC 27294 and ATCC 35828, for the PZA sensitive and resistant strains, respectively) were determined by Microplate Alamar Blue Assay (MABA) following incubation of one week at $37^{\circ} \mathrm{C}$, as previously described [14], using glycerol-alaninesalts medium (GAS) as well as protein-rich 7H12 medium. The MIC was defined as the lowest concentration of the compound effecting a reduction in fluorescence of $90 \%$ relative to the controls, and rifampin (RMP) and PZA were used as standards. Determinations were done in triplicate.

Activity against non-replicating $M$. tuberculosis under hypoxic conditions was determined using the LORA [3] by exposing the recombinant $M$. tuberculosis (pFCA-luxABCDE) to tested compounds following 10 days under anaerobic conditions. After $28 \mathrm{~h}$ of normoxic recovery, the luminescent signal was measured. As in the MABA, MICs values were defined as the lowest concentration inhibiting recovery of luminescent signal by $90 \%$ relative to bacteria-only controls. Details about the experimental assays can be seen in supplementary data.

\subsection{Cytotoxicity assays}

Cytotoxicity of the compounds was assessed against Vero cells (ATCC CCL-81) using the Promega CellTiter 96 Aqueous nonradioactive cell proliferation assay [15]. The viability of the cells was evaluated according the cellular conversion of 3-(4,5dimethylthiazol-2-yl)-5-(3-carboxymethoxyphenyl)-2-(4-

sulfophenyl)-2H-tetrazolium (MTS) into a soluble formazan product, in the presence of phenazine methosulfate (PMS). RMP was used as standard drug. $\mathrm{CC}_{50}$ is the lowest concentration of the compound which reduces MTS conversion by $50 \%$. Determinations were done in triplicate.

\section{4. $\log P$ calculation}

The estimated $\log P$ was calculated using the software Marvin [16] version 14.8.11, using the calculation plugin implemented in the software. The calculation method is based on the publication of Viswanadhan et al. [17], which is weighted by Klopman method and Physprop database data. Considered electrolyte concentrations $\left(\mathrm{Na}^{+}, \mathrm{K}^{+}\right.$and $\left.\mathrm{Cl}^{-}\right)$were $0.1 \mathrm{~mol} / \mathrm{L}$.

\section{Results and discussion}

Although several research groups are engaged in the search for active molecules, only few molecules have reached clinical trials, and in fact, since the introduction of RMP in 1967, only two new chemical entity (NCE) has reached the therapeutics, bedaquiline

Table 1

Anti-Mtb activity of POA esters $\mathbf{1}-\mathbf{6}$ against $\mathrm{H}_{37} \mathrm{Rv}$ strain.

\begin{tabular}{|c|c|c|c|c|c|}
\hline \multirow[t]{2}{*}{ Compound } & \multicolumn{3}{|c|}{$\mathrm{MIC}_{90}(\mu \mathrm{M}), \%$ inhibition } & \multirow[t]{2}{*}{$\mathrm{CC}_{50}(\mu \mathrm{M}), \%$ inhib. } & \multirow[t]{2}{*}{$\log P$} \\
\hline & GAS & 7H12 & LORA & & \\
\hline 1 & 135.5 & 602.8 & $>724(70 \%)$ & >724 (9\%) & -0.27 \\
\hline 2 & 64.0 & 281.1 & $>657(46 \%)$ & $>657$ (3\%) & 0.08 \\
\hline 3 & 72.1 & 227.4 & $>536(82 \%)$ & $>536(13 \%)$ & 0.39 \\
\hline 4 & 15.1 & 165.8 & $>480(87 \%)$ & $>480(11 \%)$ & 1.94 \\
\hline 5 & 78.4 & 322.3 & $>365(73 \%)$ & $>365(4 \%)$ & -0.72 \\
\hline 6 & 39.1 & 277.1 & $>347(83 \%)$ & $>347(13 \%)$ & -0.66 \\
\hline PZA & $>100(40 \%)$ & $>100(77 \%)$ & 45.0 & n.d. & \\
\hline RMP & 0.06 & 0.09 & 0.06 & $>100(43 \%)$ & \\
\hline
\end{tabular}


Table 2

Anti-Mtb activity of POA esters $\mathbf{1}-\mathbf{6}$ against $\mathrm{H}_{37} \mathrm{Rv}$ strain in $\mathrm{pH}$ 6.0.

\begin{tabular}{llll}
\hline \multirow{2}{*}{ Compound } & \multicolumn{4}{l}{ MIC $_{90}(\mu \mathrm{M}), \%$ inhibition } \\
\cline { 2 - 4 } & GAS & $7 \mathrm{H} 12$ & LORA \\
\hline $\mathbf{1}$ & 64.1 & $>724(88 \%)$ & $>724(57 \%)$ \\
$\mathbf{2}$ & 35.5 & $>657(87 \%)$ & 513.3 \\
$\mathbf{3}$ & 16.1 & 266.5 & 399.8 \\
$\mathbf{4}$ & 3.9 & $>480(80 \%)$ & 214.5 \\
$\mathbf{5}$ & 42.4 & $>365(85 \%)$ & $>365(61 \%)$ \\
$\mathbf{6}$ & 20.8 & $>347(88 \%)$ & 169.1 \\
$\mathbf{P Z A}$ & $>100(61 \%)$ & $>100(87 \%)$ & 44.3 \\
$\mathbf{R M P}$ & 0.08 & $<0.016$ & 0.18 \\
\hline
\end{tabular}

and delanamid. Considering this, prodrug design is considered a feasible approach to achieve new active molecules, especially chemotherapeutics. This technique consists on designing inactive molecules, which can be activated in vivo in the desired tissue/ compartment or close to it, using a carrier moiety that gives the desired characteristic to whole molecule [18]. Several examples of prodrugs can be found in literature, including some with anti-Mtb activity $[2,10,11,19]$. Here, we describe six examples of POA prodrugs, designed using an ester group to attach the carrier, which improves the lipophilicity of the molecule (property that lacks in POA), allowing this latent form to cross the lipidic membranes of Mtb.

Since POA itself is highly hydrophilic and easily ionizable in physiological pH, it cannot cross cell membrane of Mtb, and thus is inactive. By dissembling the carboxylic acid through esterification, the group becomes non-ionizable, which allows better penetration through lipid membranes, and in summary, esters can circumvent the problem of poor penetration of POA in Mtb. Moreover, the alkyl chain (carrier group) plays the role in lipophilicity (expressed as $\log \mathrm{P}$ ), modulating water solubility and penetration through mycobacterial cell membrane. Lower alkyl chain (in case of compounds $\mathbf{1}$, 2 and 3) are more water soluble than higher homologues (as compound 4), however, may present poor cell penetration. Compounds 5 and $\mathbf{6}$ were designed to achieve higher molar ratio of POA inside Mtb after hydrolysis, thereby each molecule of prodrug should deliver two molecules of active agent inside mycobacteria. These two compounds were not yet reported in literature.

The final compounds were prepared with adequate yields by each method. Method A was described by us in previous report [2] to prepare compound 3, and was also applied to prepare compounds $\mathbf{1}$ and 2. The pyrazinoyl chloride is generated in situ by thionyl chloride and readily reacts with the desired alcohol to give the corresponding ester. The classical method generally uses a base to quench the forming $\mathrm{HCl}$. This procedure can be considered a "greener" synthetic procedure, since the pyrazinoate can act as base, avoiding the addition of base. Method B was chosen to prepare compound 4 because long-chain alcohols (as 1-hexanol) present higher boiling point which become harder to evaporate. Thus,

Table 3

Anti-Mtb activity in r-PZA strain.

\begin{tabular}{lll}
\hline \multirow{2}{*}{ Compound } & \multicolumn{2}{l}{$\mathrm{MIC}_{90}(\mu \mathrm{M}), \%$ inhibition } \\
\cline { 2 - 3 } & $\mathrm{pH} 6.6$ & $\mathrm{pH} 6.0$ \\
\hline $\mathbf{1}$ & $>724(27 \%)$ & $>724(67 \%)$ \\
$\mathbf{2}$ & $>657(75 \%)$ & $>657(47 \%)$ \\
$\mathbf{3}$ & $>536(53 \%)$ & $>536(85 \%)$ \\
$\mathbf{4}$ & $>480(71 \%)$ & $>480(76 \%)$ \\
$\mathbf{5}$ & $>365(50 \%)$ & $>365(54 \%)$ \\
$\mathbf{6}$ & $>347(46 \%)$ & $>347(60 \%)$ \\
$\mathbf{P Z A}$ & $>100(43 \%)$ & $>100(48 \%)$ \\
$\mathbf{R M P}$ & 0.05 & $<0.016$ \\
\hline
\end{tabular}

substitution from bromine to pyrazinoate was considered, since the excess of alkyl halide is easily removed by chromatography. Compounds $\mathbf{5}$ and $\mathbf{6}$ were prepared by same approach, but using excess of POA. This excess was removed by washing the organic layer with basic solution.

The MICs obtained for compounds $\mathbf{1}$ to $\mathbf{6}$ are presented in Table 1. Observing the MICs for compounds $\mathbf{1}$ to $\mathbf{4}$, it is possible to verify the role played by alkyl chain of POA esters. According to the results, the more lipophilic alkyl chain, the more active compound. This corroborate to Zhang's hypothesis, since more lipophilic molecules achieve higher intracellular concentration of POA. Considering compound $\mathbf{2}$ and 3, the chlorine atom does not influence considerably in the activity, however it slightly increases the lipophilicity. In fact, the activity of $\mathbf{3}$ is slightly higher in 7H12 medium than that obtained for $\mathbf{2}$, but this difference was not observed in GAS medium. Compound $\mathbf{4}$ was the most active compound, showing MIC value much higher than the obtained for PZA, in GAS medium. However, in 7H12 medium, this good activity was not observed, showing activity comparable only to PZA.

It is very interesting as medium composition can affects the activity of presented POA esters. In previous paper [2], we reported the activity of compound 3 in Mtb using 7H9 medium (without albumin supplementation), obtaining MIC value of $3.96 \mu \mathrm{g} / \mathrm{mL}$ $(21.22 \mu \mathrm{M})$. In this report, the observed activity was 10 times lower in albumin-richer medium, suggesting the albumin can bind to these compounds. This fact may reduce its availability to go inside Mtb. In albumin-free medium (GAS), the activity is much increased, which gives the support for this hypothesis. This statement is valuable in screening tests for anti-Mtb activity, because it provides speculations about pharmacokinetic behavior of future drugs. Molecules with high albumin binding have difficulties of distribution through tissues, and consequently they will achieve lower concentrations in the local of infection that can affect the antimycobacterial activity. It seems to be a consensus that determining functional protein binding via MIC shift is important in screening procedures [20]. In this paper, this determination was performed using bovine albumin (0.5\%) supplemented in 7H12 medium. This can be an estimative of protein binding is human serum. However, serum concentration of albumin is approximately $4 \%$. Other serum proteins such as globulins and acid alpha 1-glycoprotein may also be involved in drug binding [16]. In summary, it is possible to infer this MIC shift from GAS medium to 7H12 medium will be correlated to albumin-binding in vivo, although differences in medium composition may certainly influence in this differences, mainly regarding the carbon source. More detailed studies must be performed to verify this.

It is widely known the anti-Mtb activity of PZA is $\mathrm{pH}$-dependent. It was observed that the activity of PZA increases as $\mathrm{pH}$ decreases being the optimum activity when $\mathrm{pH}$ medium is around $5.8[10,11]$. As can be seen in Table 2, the activity of POA esters does not show the same behavior. In GAS medium, the activities found were greater when $\mathrm{pH}$ changed from 6.6 to 6.0. Compound 4 must be highlighted due to its high activity in $\mathrm{pH}$ 6. This feature can increase the activity intragranuloma in vivo, where $\mathrm{pH}$ is lower than physiological. On other hand, the acidification of culture medium led to lower activity in albumin-rich medium. Possibly the albumin binding of POA esters is affected by $\mathrm{pH}$, increasing the binding. Ionization state of the compounds and of the protein may be responsible for this behavior. POA is an acid (due to carboxylic acid) and basic (due to pyrazine N's) molecule. Although the basicity of pyrazine ring is very low, the prodrugs are only basic molecules. The acidification of the medium leads to more ionized state, which difficult the passage through lipidic mycobaterial membranes.

All of the compounds showed to be practically inactive in LORA and also against PZA-resistant strain (r-PZA). However, when 
medium pH was acidified to 6.0, the activity in LORA was increased. The lipophilic compound $\mathbf{4}$ was the most active among the simple prodrugs. Certainly the lipophilicity may play the role in this activity, but the role of $\mathrm{pH}$ in LORA is not obvious. Maybe different metabolic pathway is activated in this $\mathrm{pH}$ and in addition to anaerobic conditions, favoring the POA mechanism of action by an inverse manner than in MABA. It is noteworthy that during the disease process, bacilli reside in different microenvironment including high oxygen or low oxygen content, nutrient starvation, oxidative stress, and acidic $\mathrm{pH}$, all of which interfere in their metabolism [21]. Therefore, biochemical studies should be made to define this condition. Interestingly, PZA activity is not affected by this $\mathrm{pH}$ change in LORA assay, and in conclusion, the POA esters mechanism of action may be different from PZA in LORA. Regarding r-PZA strains (Table 3), the obtained MIC showed no significant activity for the presented esters, and this could be attributed to the mechanism of resistance. POA esters have already shown activity in PZAse negative strains. Certainly, this activity is independent of PZAse activation pathway, being POA produced through hydrolysis by inespecific esterases and exerting its activity using the same mechanism of action than for PZA. A PZA derivative, 5-chloro-PZA, have also shown activity in r-PZA strains [22,23], and it is considered a molecule with a unique mechanism of action, different from PZA mechanism. It is possible the r-PZA strain here used is resistant to PZA not only by absence of PZAse activity, but through final target mutation indeed. It is important to reinforce the role of $\mathrm{pH}$ is maintained even in r-PZA and LORA, although the activity is still far from expected.

Duplicated prodrugs $\mathbf{5}$ and $\mathbf{6}$ have shown activity comparable to compounds $\mathbf{2}$ and $\mathbf{3}$. These compounds were designed to achieve higher molar ratio inside mycobacteria after hydrolysis, generating 2 mol of POA to each mole of prodrug. Regarding this, it was expected the activity of these compounds should be twice higher than non-duplicated compound. Since compound $\mathbf{5}$ can be considered a duplication of compound $\mathbf{1}$, the activity fulfilled this objective, because obtained MIC for $\mathbf{5}$ is half than obtained for $\mathbf{1}$ both in 7H12 and GAS media. However, changes in lipophilicity must be considered for POA duplicates, since pyrazinoate moiety decreases the lipophilicity of whole molecule. It can be observed in Table 1 the $\log P$ values for duplicated prodrugs $\mathbf{5}$ and $\mathbf{6}$ are low. Possibly more lipophilic duplicates would present increased activity, as stated for the simple esters. In future work we intend to evaluate a new set of duplicates to achieve higher activity.

The role of $\mathrm{pH}$ is also valid for duplicate prodrugs. It can be observed lowering the $\mathrm{pH}$ to 6.0 led to an increase of MIC activity, even in resistant strain r-PZA and in LORA. Specifically in LORA, compound $\mathbf{6}$ was especially active, being the most promising of the series, exhibiting higher activity than the lipophilic prodrug 4. However, compound $\mathbf{5}$ has shown poor activity, probably due to lower lipophilicity than compound $\mathbf{6}$. In any case, the activity of our compounds is far from the activity of PZA in LORA.

Regarding the cytotoxicity of the presented compounds, none was considered significantly cytotoxic. At highest concentration evaluated, the most cytotoxic compounds $\mathbf{3}$ and $\mathbf{6}$ showed only 13\% of inhibition of Vero cells. It means the POA esters are highly selective to mycobacteria, and do not present significant toxicity to human cells. In fact, all of the POA esters are less cytotoxic than RMP. This can be considered a concern in chemotherapeutics, since several compounds with high MIC activity also show high cytotoxicity. Previous reports presenting compounds with high LORA activity have also shown toxicity values in the same order of magnitude than the LORA activity. As example, a nitrofuran presented by Lilienkampf et al. [4] have shown $\mathrm{IC}_{50}$ of $15 \mu \mathrm{M}$ to Vero cells, whereas the MIC to Mtb was $6 \mu \mathrm{M}$. Other studies regarding cytotoxicity in different cell lines, including macrophages, are being performed by us, but preliminary results indicate low cytotoxicity even in these cells.

\section{Conclusion}

In conclusion, the presented POA esters showed moderate antiMtb activity, improved in $\mathrm{pH}$ 6.0, especially in albumin-free medium. It is noteworthy the activity in LORA, which is an important subpopulation in TB infection, and very low cytotoxicity of the compounds. Novel duplicated prodrugs of POA showed interesting activity, and a new set of duplicated compounds will be synthesized and evaluated considering these results in order to improve the anti-Mtb activity.

\section{Funding: None.}

\section{Competing interests: None declared.}

\section{Ethical approval: Not required.}

\section{Acknowledgments}

Authors are grateful to Fundação de Amparo à Pesquisa do Estado de São Paulo (FAPESP, grant 2013/20479-9) for financial support to this work, and to Coordenação de Aperfeiçoamento de Pessoal de Nivel Superior (CAPES) for the scholarship to M.F.C.

\section{Appendix A. Supplementary data}

Supplementary data related to this article can be found at http:// dx.doi.org/10.1016/j.tube.2016.04.002

\section{References}

[1] WHO, World Health Organization. Global tuberculosis report 2014. Geneva: WHO Press; 2014. Available from: http://www.who.int/tb/publications/ global_report/en/.

[2] Fernandes JPS, Pavan FR, Leite CQF, Felli VMA. Synthesis and evaluation of a pyrazinoic acid prodrug in Mycobacterium tuberculosis. Saudi Pharm J 2013;22:376-80.

[3] Cho SH, Warit S, Wan B, Hwang CH, Pauli GF, Franzblau SG. Low-oxygen-recovery assay for high-throughput screening of compounds against nonreplicating Mycobacterium tuberculosis. Antimicrob Agents Chemother 2007;51:1380-5.

[4] Lilienkampf A, Mao J, Wan B, Wang Y, Franzblau SG, Kozikowski AP. Structureactivity relationships for a series of quinoline-based compounds active against replicating and nonreplicationg Mycobacterium tuberculosis. J Med Chem 2009;52:2109-18.

[5] Villar R, Vicente E, Solano B, Pérez-Silanes S, Aldana I, Maddry JA, Lenaerts AJ, Franzblau SG, Cho SH, Monge A, Goldman RC. In vitro and in vivo antimycobacterial activities of ketone and amide derivatives of quinoxaline 1,4di-N-oxide. J Antimicrob Chemother 2008;62:547-54.

[6] Khoje AD, Kulendrn A, Charnock C, Wan B, Franzblau S, Gundersen LL. Synthesis of non-purine analogs of 6-aryl-9-benzylpurines, and their antimycobacterial acitivies. Compounds modified in the imidazole ring. Bioorg Med Chem 2010:18:7274-82.

[7] Pieroni M, Wan B, Cho S, Franzblau SG, Constantino G. Design, synthesis and investigation on the structure-activity relationships of $\mathrm{N}$-substituted 2aminothiazole derivatives as antitubercular agents. Eur J Med Chem 2014;72:26-34.

[8] Zhang Y, Wade MM, Scorpio A, Zhang H, Sun ZH. Mode of action of pyrazinamide: disruption of Mycobacterium tuberculosis membrane transport and energetics by pyrazinoic acid. J Antimicrob Chemother 2003;52:790-5.

[9] Sayahi H, Zimhony O, Jacobs WR, Shekhtman A, Welch JT. Pyrazinamide, but not pyrazinoic acid, is a competitive inhibitor of NADPH binding to Mycobacterium tuberculosis fatty acid synthase I. Bioorg Med Chem Lett 2011;21: 4804-7.

[10] Cynamon MH, Klemens SP, Chou TS, Gimi RH, Welch JT. Antimycobacterial activity of a series of pyrazinoic acid-esters. J Med Chem 1992;35:1212-5.

[11] Cynamon MH, Gimi R, Gyenes F, Sharpe CA, Bergmann KE, Han HJ, Gregor LB, Rapolu R, Luciano G, Welch JT. Pyrazinoic acid-esters with broad-spectrum invitro antimycobacterial activity. J Med Chem 1995;38:3902-7. 
[12] Bergmann KE, Cynamon MH, Welch JT. Quantitative structure-activity relationships for the in vitro antimycobacterial activity of pyrazinoic acid esters. J Med Chem 1996;39:3394-400.

[13] Fernandes JPS, Felli VMA. Evaluation of the influence of base and alkyl bromide on synthesis of pyrazinoic acid esters through fatorial design. Quim Nova 2009;32:2464-6.

[14] Collins L, Franzblau S. Microplate Alamar blue assay versus BACTEC 460 system for high-throughput screening of compounds against Mycobacterium tuberculosis and Mycobacterium avium. Antimicrob Agents Chemother 1997;41:1004-9.

[15] Gao W, Kim JY, Anderson JR, Akopian T, Hong S, Jin JY, Kandror O, Kim JW, Lee IA, Lee SY, McAlpine JB, Mulugeta S, Sunoqrot S, Wang Y, Yang SH, Yoon TM, Goldberg AL, Pauli GF, Suh JW, Franzblau SG, Cho S. The cyclic peptide ecumicin targeting $\mathrm{ClpC} 1$ is active against Mycobacterium tuberculosis in vivo. Antimicrob Agents Chemother 2014;59:880-9.

[16] Chemaxon Inc. Marvin version 14.8.11. 2014.

[17] Viswanadhan VN, Ghose AK, Revankar GR, Robins RK. J Chem Inf Comput Sci 1989;29:163-72.
[18] Wermuth CG. Designing prodrugs and bioprecursors. In: Wermuth CG, editor The practice of medicinal chemistry. 3rd ed. London: Academic Press; 2008. p. $721-46$.

[19] Chung MC, Ferreira EI, Santos JL, Giarolla J, Rando DG, Almeida AE Bosquesi PL, Menegon RF, Blau L. Prodrugs for treatment of neglected diseases. Molecules 2008;13:616-77.

[20] Franzblau SG, DeGroote MA, Cho SH, Andries K, Nuermberger E, Orme IM, Mdluli K, Angulo-Barturen I, Dick T, Dartois V, Lenaerts AJ. Comprehensive analysis of methods used for the evaluation of compounds against Mycobacterium tuberculosis. Tuberculosis 2012;92:453-88.

[21] Zhang Y, Yew WW, Barer MR. Targeting persisters for tuberculosis control. Antimicrob Agents Chemother 2012;56:2223-30.

[22] Speirs RJ, Welch JT, Cynamon MH. Activity of n-propyl pyrazinoate against pyrazinamide-resistant Mycobacterium tuberculosis: investigations into mechanism of action of and mechanism of resistance to pyrazinamide. Antimicrob Agents Chemother 1995;39:1269-71.

[23] Cynamon MH, Speirs RJ, Welch JT. In vitro antimycobacterial activity of 5chloropyrazinamide. Antimicrob Agents Chemother 1998;42:462-3. 